\title{
ARAŞTIRMA/RESEARCH
}

\section{Laparoskopik cerrahinin gözden kaçabilen sorunu: trokar yeri kanamas1}

\author{
Overlooked problem of laparoscopic surgery: trocar site bleeding \\ Oğuzhan Dincel ${ }^{1}$, Fatih Başak ${ }^{2}$, Erdem Kınac1 ${ }^{3}$ \\ ${ }^{1}$ Adıyaman Üniversitesi Tip Fakültesi, Genel Cerrahi Ana Bilim Dalı, Adıyaman, Turkey \\ 2Ümraniye Eğitim ve Araștırma Hastanesi, Genel Cerrahi Kliniği, İstanbul, Turkey \\ ${ }^{3}$ İstanbul Eğitim ve Araştırma Hastanesi, Genel Cerrahi Kliniği, İstanbul, Turkey
}

Cukurova Medical Journal 2016;41(4):767-770.

\begin{abstract}
Purpose: Trocar site bleeding is a complication which can be overlooked and prevented if pay attention. It can lead to unwanted problems during surgery if not noticed. In our study, we aimed to investigate the problem that can be seen in every laparoscopic surgery.

Material and Methods: We reviewed the cases who underwent laparoscopic cholecystectomy in our clinic between September 2012 - September 2015. Patients with trocar site bleeding after surgery were enrolled into the study. Demographic and postoperative follow-up data of patients were recorded.

Results: Eight of 350 patients (2.3\%) with laparoscopic cholecystectomy were taken diagnosis of intra-abdominal hemorrhage after postoperative examinations. Three of the patients were men and five were women, mean age was $45 \pm 15.9$ (19-72). Four patients (M/W: 1/3) required reoperation to control bleeding and hematoma drainage. Medical supportive treatment was adequate for the remaining patients. The patients were discharged without any complication.

Conclusion: Trocar site bleeding can be prevented by application of appropriate methods. In particular, special care should be taken when inserting and removing the trocars during the operation. During the entry of secondary trocars it should be accompanied by transillumination and at the end of the operation trocars should be removed from their places under direct vision.

Key words: Laparoscopy; trocar; bleeding; complication
\end{abstract}

Öz

Amaç: Trokar yeri kanamaları gözden kaçabilen ve dikkat edilirse önlenebilir bir komplikasyondur. Ameliyat esnasinda fark edilmez ise istenmeyen problemlere yol açabilir. Çalışmamızda her laparoskopik cerrahide görülebilecek bu problemi irdelemeyi amaçladik.

Gereç ve Yöntem: Kliniğimizde 2012 Eylül - 2015 Eylül arasında laparoskopik kolesistektomi yapilan hastalar tarandi. Ameliyat sonrasında trokar yeri kanaması olan hastalar çalışmaya alındı. Hastaların dosyalarında kayıtlı demografik verileri, uygulanan tedaviler ve takipleri incelendi.

Bulgular: Laparoskopik kolesistektomi yapilan 350 hastanin sekiz tanesi $(\% 2,3)$ ameliyat sonrasindaki incelemelerde batın içi kanama tanısı aldı. Hastaların üçü

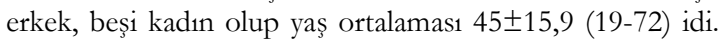
Dört hastaya (E/K: 1/3) tekrar ameliyat gerekli görüldü, kanama kontrolü ve hematom drenaj1 yapıldı. Diğer dört hastaya medikal destek tedavisi yeterli oldu. Hastalar sorunsuz taburcu edildi.

Sonuç: Trokar yeri kanamaları uygun yöntemler uygulandı̆̆1 zaman önlenebilir. Özellikle operasyon esnasında trokar yerleştirilirken ve çıkartılırken dikkatli olunmalıdır. Trokar girişi esnasında ikincil trokarlar transilüminasyon eşliğinde konulmalı ve operasyon bittikten sonra trokarlar yerlerinden direkt görüş altında çıkarılmalıdır.

Anahtar kelimeler: Laparoskopi; trokar; kanama; komplikasyon 


\section{GİRİ̧̧}

Laparoskopik tekniklerin gelişmesi cerrahi alanda büyük değişimler yapmıştır. Ameliyat sonrası azalmış ağrı, normal aktiviteye daha hızlı geri dönüş ve daha az komplikasyon faydalarının yanında, laparoskopik batın cerrahisinde beklenmedik değişik komplikasyonlar görülmektedir. Bağırsak yaralanmas1 veya büyük damar yaralanması nadir fakat potansiyel olarak yaşamı tehdit eden genellikle ilk trokar girişi sırasında meydana gelen komplikasyonlardir ${ }^{1,2}$.

Laparoskopik prosedürleri takiben gelişen major komplikasyonların tamamı yaklaşı 1000 vakada 1,4 oranındadır ${ }^{3}$. Laparoskopik cerrahi sonrası giriş yeri komplikasyonlarının görülme sıklığı, yaklaşık 100,000 vakada 21 olarak kabul edilir ve trokar yerinin insizyonu ve trokar çapının artışı ile oransal artış göstermektedir ${ }^{4-6}$. Laparoskopik ameliyatlarda trokar girişi ile ilişkili ortaya çıkan beklenmedik komplikasyonlar; gastrointestinal yaralanma (1000'de $0,6)$, genito-üriner yaralanma (1000'de 0,3), damar yaralanmas $1(1000$ 'de 0,1$)$ ve omentum yaralanmas1 $(1000$ 'de 0,4$)$ şeklinde görülebilmektedir ${ }^{7,8}$.

Laparoskopik cerrahi sonrası trokar yeri ile ilişkili minör kanamalar nadir görülmesi sebebiyle çoğu zaman ihmal edilmektedir, ancak devam eden kanama durumlarında hastanın hayatını tehdit edebilir. Bu çalışmanın amacı basit olarak görülebilen ve ihmal edilen bu konuya olgu serisi ile dikkat çekmek ve literatür eşliğinde tartışmaktır.

\section{GEREÇ VE YÖNTEM}

Trokar yeri kanaması olgularını değerlendirmek amacıyla tanımlayıcı retrospektif bir çalışma planlandı. Kliniğimizde 2012 Eylül - 2015 Eylül arasinda tek cerrah (OD) tarafindan 350 laparoskopik kolesistektomi yapıldı. Bu olguların tamamında trokar giriş yeri, kullanılan trokar boyutlar1 ve sayıs1 aynı idi. Dört adet tekrar kullanılabilir trokar kullanıldı. Umbilikal $(10 \mathrm{~mm})$, epigastrik $(10 \mathrm{~mm})$, sağ subkostal $(5 \mathrm{~mm})$ ve sağ McBurney $(5 \mathrm{~mm})$ noktaları trokar giriş yerleri olarak kullanıldı. İlk trokar Veress eşliğinde insuflasyon ile umbilikal bölgeden girildi. Umbilikal trokar yerinin fasyası kapatıldı.

Ameliyat sonrası dönemde trokar yeri kanaması nedeniyle tedavi olan olguların muayene bulguları, demografik verileri, yapılan müdahale şekli ve sonuçları incelendi.

\section{İstatistiksel analiz}

Verilerin analizinde tanımlayıcı istatistikler, sürekli değişkenler için ortalama ve standart sapma; kategorik veriler için ise sayı ve yüzde kullanıldı.

\section{BULGULAR}

Değerlendirmeye alınan 350 hastadan 220'si erkek, 130 'u kadın idi. Hastaların yaş aralığ1 19-72 olup yaş ortalaması 45 $\pm 15,9$ idi. Bu hastalardan sekizi $(\% 2,3)$ laparoskopik kolesistektomi ameliyatı sonrası trokar yeri kanaması nedeniyle takip ve tedavi altına alındı. Kanama görülen hastaların beşi kadın, üçü erkek idi. İki hastada hipertansiyon, bir hastada ise diyabet hastalığ1 vardı. Antikoagülan kullanan hasta yoktu.

Dört hastada (bir erkek, üç kadın) ameliyat sonrası 2. ve 8. saatler arasinda genel durum bozukluğu, hipotansiyon, taşikardi ve hemoglobin düşüklüğü nedeniyle inceleme yapıld. Hastaların batın ultrasonografisi ve tomografisinde sorun belirgin olarak tespit edilemedi. Hastalar batın içi kanama şüphesi ile acil ameliyata alındı. Öncelikle umbilikal trokar yerinden tekrar laparoskopik bakı ile karın içi değerlendirildi. Olguların tamamında karın içinde yaygın kanama/hematom görüldü. Açık cerrahiye gerek duyulan hastaların dikkatli eksplorasyonunda kanama odağı olarak üç olguda epigastrik, bir olguda umbilikal trokar yeri olduğu tespit edildi. Ameliyata alınan hastalarda ek yaralanma görülmedi.

Kanama şüphesi olan ve acil cerrahi girişim gerekmeyen diğer dört hastanın üçünde umbilikal bölgeden suprapubik ve sol lomber bölgeye uzanan yaygın cilt altı ekimoz görüldü. Diğer bir hastada ise sağ mc-burney noktasindaki trokar yerinden sağ lomber bölgeye uzanan hematom/ekimoz tespit edildi. Hastalara sık1 kompres uygulaması, medikal destek tedavisi yapıld1. Bu hastalardan sadece bir tanesine kan transfüzyonu uygulandı. Hastalarda tekrar kanama görülmedi. Tüm hastalar uygun müdahaleler sonrası sorunsuz şekilde taburcu edildi.

\section{TARTIŞMA}

Trokar yeri (port yeri) komplikasyonları; girişe bağlı komplikasyonlar ve postoperatif komplikasyonlar şeklinde gruplandırılmış olup tüm yaş gruplarında ve her iki cinsiyette de bildirilmiştir. Trokar yeri kanaması için obesiteye bağlı kalın karın duvarı olması, ekplorasyon için insizyonun genişletilmesi, uzun trokar gereksinimi, artmış yağ dokusundan 
dolay1 enstrümanlarda kısıtlı hareketlilik suçlanmaktadır. Trokar yeri kanamaların görüldüğü en yaygın prosedür kolesistektomi olgularıdır ${ }^{9}$. Bu ilişkinin sebebi olarak kolesistektomi vakalarının artan siklı̆g ve normal bir prosedür gibi görülmesinden kaynaklanabileceği düşünülebilir. Çalışmamızda hastaların obesite durumu ve insizyon genişletme ile ilgili istatistiki değerlendirme yapılamamıştır. Bu durumun sebebi olgu sayımızın azlığ1 ve retrospektif çalışma dizaynıdır. Bu konuda daha geniş ve kontrollü çalışmalara ihtiyaç bulunmaktadır.

Yapılan bir çalışmada trokar giriş yeri kanama sıklığı $\% 0,7$ olarak bildirilmiştir. Tüm kanamaların ikincil trokar yerinde görüldüğ̈ ifade edilmiștir. Epigastrik damarların yaralanması ikincil trokar yerleştirme sırasında dikkatsizlik ile ilișkili olabilir. Bu nedenle direk görüş altında ve karın duvarı aydınlatılarak (trans-ilümünasyon) yerleştirilmesi önerilmektedir. Karın duvarından oluşan kanamalar trokarın musküler ve subkutan tabakadaki kanamalara tamponad etkisinden dolayı trokar çıkarılana kadar görülmeyebilir ${ }^{10} . \quad \mathrm{Bu}$ nedenle trokarların girişi esnasında direk görüşün yanında trokarın çıkarılması esnasında ve çıkardıktan sonra da dikkatle incelenmelidir. Bunun sonucunda kanama noktaları genellikle tespit edilip koterizasyon ile tedavi edilebilir. Ancak durmayan kanamalarda açık ameliyata geçiş gerekebilirr10,11. Malik ve arkadaşlarının $^{11}$ yaptığı bir çalışmada 1046 laparoskopik kolesistektomi vakasında ekstra-biliyer komplikasyonlar değerlendirilmiş olup $13(\% 1,2)$ hastada trokar yeri kanaması görülmüştür. Ancak beş hastada durdurulamayan kanama nedeniyle aç1k ameliyata geçilmiştir. Çalışmamızda ameliyat sonrası erken dönemde saptanan trokar yeri kanama vakaları sunulmuştur.

Ufak trokar $(5 \mathrm{~mm})$ yerindeki kanamalarda ve obez hastalarda kanama kontrolü için cilt insizyonunu büyütmek gerekebilir ve bu şekilde daha geniş yara izi oluşabilir. Bu durumu engellemek için değişik yöntemler ve hemostatik ajanlar kullanılmıştır. Trokar yerine uygun Surgicel Johnson \& Johnson Medical, Inc., Arlington, Texas) tampon kullanımı önerilmiştir ${ }^{11}$. Ayrıca trokar yerine foley kateter yerleştirilerek şişirilir ve aynı zamanda yumuşak bir çekiş ile tamponad uygulanabilir. Ayrıca, doğrudan laparoskopik görüş altında karın duvarına emilebilir U-dikiş yerleştirilebilir. Trokar yerindeki fasyayı kapatmak için geliştirilen bir çok özel alet aynı zamanda karın duvarı kanamalarının idaresinde de yararlı olabilir12-15. Bizim serimizde sekiz $(\% 2,3)$ hastada kanama görüldü, dört hastada ikinci trokar yerinde gelişmiş olup geriye kalan dört hastada ilk trokar yerinde (umbilikal bölge) tespit edildi. Trokar kullanımında literatürde önerilen trans-ilümünasyon ile giriş ve gözlem altında çıkarılma yöntemleri, uygulamamızda rutin değildir.

Minör vasküler yaralanma olarak adlandırmanın nedeni aort, vena kava inferior ve ilyak arterlerin komplikasyonlarının şiddetinden daha az olmasındandır. Ancak hiçbir şekilde bunları minör komplikasyon olarak adlandırmak doğal değildir. En s1k minör vasküler yaralanma inferior epigastrik damarda olanıdır ve laparoskopik fitık onarımlarında $\% 2,5$ oranında görülebilmektedir ${ }^{16}$. Adisa ve ark.'nın ${ }^{17}$ yaptığı bir çalışmada; 242 hastaya yapılan laparoskopik cerrahide trokar yeri, trokar girilirken ve operasyon sonunda çıkartıllırken gözlenmiş ve sadece bir $(\% 0,4)$ hastada trokar yeri kanamas1 görülmüştür. $\mathrm{Bu}$ hastaya $\mathrm{da}$ insizyon yeri eksplorasyonu ve kanayan damara bağlama uygulanmıştır. Çalışmamızda dört $(\% 1,1)$ hastada kanama cerrahi müdahale (bağlama) ile durdurulmuş olup ek organ yaralanmasina rastlanmadi. Geriye kalan dört hastada medikal destek tedavisi yeterli oldu.

Ulusal literatürde sadece trokar yeri kanamasını ele alan yayın görülmedi. Öztürk ve ark. ${ }^{18}$ laparoskopik kolesistektomi kanama komplikasyonları ile ilgili, olgu serisi şeklindeki çalışmasında; 865 laparoskopik kolesistektomi hastasının birinde $(\% 0,1)$ trokar yeri kanaması görülmüș ve bağlama ile kontrol altına alınmıştır. Mevcut çalışmada, görülebilecek kanamaların hayatı tehdit edebilecek önemli problemlere yol açabileceği bildirilmiştir. Bizim çalışmamızda, dört hastaya takiplerde hayatı tehdit edecek duruma gelmesi nedeniyle acil cerrahi müdahale yapildı.

$\mathrm{Bu}$ çalışmanın ana kısıtlayıcı faktörü çalışmanın retrospektif dizaynıdır. Çalışmamızda saptanan kanama oranı $(\% 2,3)$ mevcut literatürden $(\% 0,7)$ yüksektir. $\mathrm{Bu}$ durumun açılaması olarak; olgularımızda trokarların girişi esnasında transilüminasyon yapılmaması ve ameliyat sonunda kontrol yapılmadan trokar çıkarılması sonucu, kanamaların ameliyat sırasında görülmediği kanısına varılabilir. Ancak çalışmamızda trokar giriş ve çıkarma sırasındaki kontrol yöntemlerinin etkinliğini araştırmadık. Bu araştırma için prospektif kontrollü çalışmalara ihtiyaç vardır. Mevcut çalışmadan sonra 
kliniğimizde laparoskopik trokar girilmesi ve çıkarılması ile ilgili algoritmalar oluşturuldu.

Trokar girişleri esnasında gelişebilecek minör damar yaralanma riskinden dolayı ikincil trokarların transilüminasyon eşliğinde konulması ve direkt görüş altında çıkarılmasına önem verilmelidir. Minör trokar yeri kanamalarının hayatı tehdit edebilecek kadar önemli olabileceği göz önünde tutulmalıdır.

\section{KAYNAKLAR}

1. Shea JA, Healey MJ, Berlin JA, Clarke JR, Malet PF, Staroscik RN et al. Mortality and complications associated with laparoscopic cholecystectomy. A meta-analysis. Ann Surg. 1996;224:609-20.

2. Jansen FW, Kolkman W, Bakkum EA, de Kroon CD, Trimbos-Kemper TC, Trimbos JB. Complications of laparoscopy: An inquiry about closed- versus open-entry technique. Am J Obstet Gynecol. 2004;190:634-8.

3. Jansen FW, Kapiteyn $\mathrm{K}$, Trimbos-Kemper T, Hermans J, Trimbos JB. Complications of laparoscopy a prospective multicentre observational study. Br J Obstet Gynaecol. 1997;104:595-600.

4. Aziz R. Practical Manual of Operative Laparoscopy. New York, Springer-Verlag, 1992.

5. Kadar N, Reich H, Liu CY, Manko GF, Gimpelson R. Incisional hernias after major laparoscopic gynecologic procedures. Am J Obstet Gynecol. 1993;168:1493-5.

6. Chiu CC, Lee WJ, Wang W, Wei PL, Huang MT. Prevention of trocar-wound hernia in laparoscopic bariatric operations. Obes Surg. 2006;16:913-8.

7. Mc Gurgan P, P Donovan P. Optical versus as an entry technique. Gynaecological Endoscopy. 1999;8:379-92.
8. Mettler I, Schmidt EH, Frank V, Semm K. Laparoscopic entry and its complications. Gynaecol Endosc. 1999;8:383-9.

9. Fuller J, Ashar BS, Carey-Corrado J. Trocarassociated injuries and fatalities: An analysis of 1399 reports to the FDA. J Minim Invasive Gynecol. 2005;12:302-7.

10. Karthik S, Augustine AJ, Shibumon MM, Pai MV. Analysis of laparoscopic port site complications: A descriptive study. J Minim Access Surg. 2013;9:59-64.

11. Malik AM, Laghari AA, Mallah Q, Hashmi F, Sheikh U, Talpur KA. Extra-biliary complications during laparoscopic cholecystectomy: How serious is the problem? J Minim Access Surg. 2008;4:5-8.

12. Rastogi V, Dy V. Control of port-site bleeding from smaller incisions after laparoscopic cholecystectomy surgery: a new, innovative, and easier technique. Surg Laparosc Endosc Percutan Tech. 2002;12:224-6.

13. Kiani S, Brecht ML, Lovinger K, Poston RS. Managing port-site bleeding during less invasive coronary artery bypass grafting. Heart Surg Forum. 2012;15:E272-6.

14. McBrearty A, Blake G. Avoiding port site bleeding in laparoscopic cholecystectomy. Ann R Coll Surg Engl. 2014;96:170.

15. Ruiz-Tovar J, Priego-Jimenez P, Paiva-Coronel GA. Use of Foley's catheter to control port-site bleeding in bariatric surgery. Obes Surg. 2012;22:306-8.

16. Krishnakumar S, Tambe P. Entry Complications in Laparoscopic Surgery. J Gynecol Endosc Surg. 2009;1:4-11.

17. Adisa AO, Alatise OI, Agbakwuru EA, Akinola DO, Adejuyigbe O. Wound complications following laparoscopic surgery in a nigerian hospital. Niger J Surg. 2014;20:9.

18. Öztürk A, Atalay T, Karaköse Y, Çipe G, Akıncı ÖF. Laparoskopik kolesistektomi sonrası kanama: Nadir ama önemli bir komplikasyon. Şişli Etfal Eğitim ve Araştırma Hastanesi Tıp Bülteni. 2015;49:274-8. 